\title{
KNOWLEDGE AND ATTITUDE OF PARENTS OR CARETAKERS REGARDING TRANSMISSIBILITY OF CARIES DISEASE
}

\author{
Vivien T. SAKAI ${ }^{1}$, Thais M. OLIVEIRA ${ }^{2}$, Thiago C. SILVA ${ }^{1}$, Ana Beatriz S. MORETTI ${ }^{1}$, \\ Dafna GELLER-PALTI ${ }^{1}$, Vivian A. BIELLA ${ }^{1}$, Maria Aparecida A. M. MACHADO ${ }^{3}$
}

\author{
1-DDS, MSc, Gaduate Student, Department of Pediatric Dentistry, Orthodontics and Public Health, Bauru School of Dentistry - University of \\ São Paulo, Bauru, Brazil. \\ 2- DDS, MSc, PhD, Department of Pediatric Dentistry, Orthodontics and Public Health, Bauru School of Dentistry - University of São Paulo, \\ Bauru, Brazil. \\ 3- DDS, MSc, PhD, Associate Professor, Department of Pediatric Dentistry, Orthodontics and Public Health, Bauru School of Dentistry -
} University of São Paulo, Bauru, Brazil.

Corresponding address: Profa. Dra. Maria Aparecida de Andrade Moreira Machado - Al. Octávio Pinheiro Brisolla, 9-75 - Vl. Universitária - Bauru - SP - Brazil. 17012-901 - Phone: 5514 3235-8218 - Fax : 5514 3223-4679 - e-mail: mmachado@fob.usp.br

Received: August 17, 2007 - Modification: September 20, 2007 - Accepted: September 28, 2007

\begin{abstract}
D

ental caries is a transmissible infectious disease in which mutans streptococci are generally considered to be the main etiological agents. Although the transmissibility of dental caries is relatively well established in the literature, little is known whether information regarding this issue is correctly provided to the population. The present study aimed at evaluating, by means of a questionnaire, the knowledge and usual attitude of 640 parents and caretakers regarding the transmissibility of caries disease. Most interviewed adults did not know the concept of dental caries being an infectious and transmissible disease, and reported the habit of blowing and tasting food, sharing utensils and kissing the children on their mouth. 372 (58.1\%) adults reported that their children had already been seen by a dentist, $264(41.3 \%)$ answered that their children had never gone to a dentist, and $4(0.6 \%)$ did not know. When the adults were asked whether their children had already had dental caries, 107 (16.7\%) answered yes, 489 (76.4\%) answered no, and 44 (6.9\%) did not know. Taken together, these data reinforce the need to provide the population with some important information regarding the transmission of dental caries in order to facilitate a more comprehensive approach towards the prevention of the disease.
\end{abstract}

Key words: Children. Dental caries. Parents. Streptococcus mutans. Transmissibility.

\section{INTRODUCTION}

Dental caries is a transmissible infectious disease in which mutans streptococci (MS) are generally considered to be the main etiological agents ${ }^{5-7,20,26}$. Streptococcus mutans and Streptococcus sobrinus are the most prevalent caries-associated organisms from humans ${ }^{6,11}$. As in many infectious diseases, colonization by pathogens is required before the disease can occur ${ }^{20}$.

MS are spread vertically in the population, mostly but not exclusively from mothers to their children, during a short period around 2 years of age $e^{5,6,16,18,26}$. Studies using phenotyping and/or genotyping methods strongly suggest that the mother is the major primary source of infection for children who carry $S$. mutans and/or $S$. sobrinus strains $^{1,9,17,26}$, and that saliva is the main vehicle by which transfer of MS may occur ${ }^{8,13}$. However, new genotypes not detected in mothers have also been reported to colonize children during longitudinal studies, suggesting that additional and extra-familial transmission sometimes occurs, perhaps from other caretakers ${ }^{10,16,18,20,26}$.

The rate and degree of transmission depend on many possible factors, including the degree of infection of the parent, caretaker or playmate, the frequency of contact with the infant and his/her diet and immune status ${ }^{21}$. In addition, early acquisition of MS is a major risk factor for early childhood caries $^{4}$ and future caries experience ${ }^{12,15,22}$.

Although the transmissible nature of dental caries is relatively well established in the literature, little is known whether information regarding this issue is correctly provided to the population. Therefore, the aim of the present study was to evaluate, by means of a questionnaire, the information and usual attitude of parents and caretakers regarding the transmissibility of caries disease. 


\section{MATERIALAND METHODS}

A questionnaire was designed to assess the knowledge and attitude of parents or caretakers of 0 to 5-year-old children regarding the transmissibility of cariogenic bacteria (Figure 1). It contained objective questions and was administered by trained interviewers to the adults who took the children to a national vaccination campaign. Informative material on the subject was distributed afterwards.

Results were expressed as a number and percentage of respondents for each question. Microsoft Excel was used for data analysis and presentation.

\section{RESULTS}

A total of 640 adults were interviewed. Among them, 544 $(85.0 \%)$ were the children's parents, $55(8.6 \%)$ were their grandparents, $25(3.9 \%)$ were their uncles or aunts, $7(1.1 \%)$ were the babysitters and $9(1.4 \%)$ were other children's relatives.

Out of 640 children, $333(52.0 \%)$ were males and 307 $(48.0 \%)$ were females. The children were divided into 6 groups, according to their ages (Table 1).

$465(72.6 \%)$ adults answered that dental caries is a disease, $138(21.6 \%)$ reported that it is not a disease and 37 $(5.8 \%)$ did not know. When they were asked whether dental caries could be transmitted from person to person, 376 (58.7\%) answered yes, 218 (34.1\%) answered no and 46

Name of the child:

Age:

Gender: ( ) male ( ) female

Degree of relationship with the child:

\section{Questionnaire}

1- Is dental caries a disease?

() yes () no () do not know

2- Can dental caries be transmitted from person to person?

() yes ( ) no () do not know

3- Do all the members of the family have their own toothbrush?

() yes () no () do not know

4- Do you blow and taste food or share utensils with the child?

() yes ( ) no () do not know

5- Do you kiss the child's mouth?

() yes ( ) no () do not know

6- Has the child ever gone to a dentist?

() yes ( ) no ( ) do not know

7- How often does the child go to the dentist?

( ) with an interval shorter than 6 months

( ) every 6 months

() once a year

( ) with an interval longer than a year

8- Has the child ever had dental caries?

() yes ( ) no () do not know

9- Have you ever had dental caries?

() yes ( ) no () do not know

10- Do you believe that the development of an anti-caries vaccine is possible?

() yes () no ( ) do not know

FIGURE 1- Questionnaire applied to assess the knowledge and attitude of the parents or caretakers of 0 to 5-year-old children regarding the transmissibility of dental caries 


\section{$(7.2 \%)$ did not know.}

Almost $100 \%$ of the adults reported that each member of their family has his or her own toothbrush. 375 (58.6\%) adults were used to blow and taste food or share utensils with the children, 262 (40.9\%) were not and $3(0.5 \%)$ did not know. Additionally, 233 (36.4\%) adults reported to kiss the children on their mouth, whereas 407 (63.3\%) did not have this habit.

Regarding children's oral health care, 372 (58.1\%) adults reported that the children had already been seen by a dentist, $264(41.3 \%)$ reported that the children had never gone to a dentist and $4(0.6 \%)$ did not know. Figure 2 shows the distribution of the children who had or had not gone to the dentist, according to their ages. The frequency of the children's visit to the dentist is shown in Figure 3.

When the adults were asked whether the children had already had dental caries, $107(16.7 \%)$ answered yes, 489 (76.4\%) answered no, and 44 (6.9\%) did not know. Figure 4

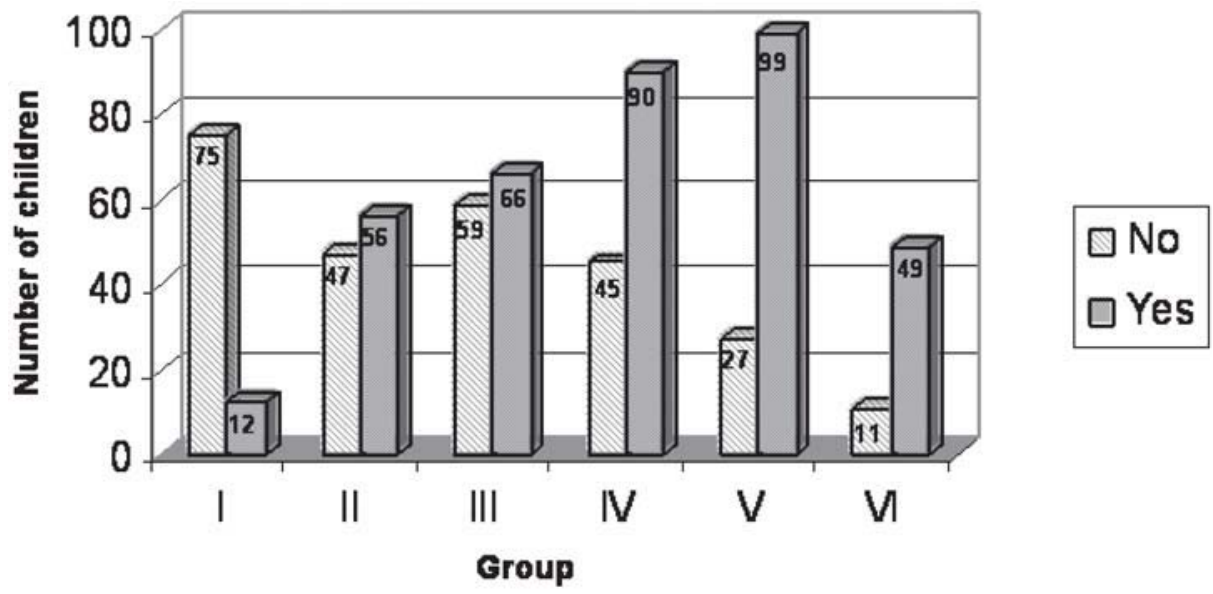

FIGURE 2- Distribution of the children who had already or had not yet gone to the dentist, according to their age

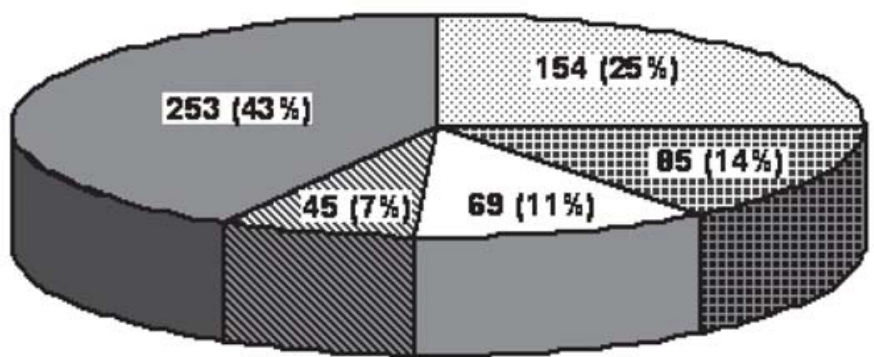

$$
\begin{aligned}
& \text { 图 }<6 \text { months } \\
& \# 6 \text { months } \\
& \square \text { once a year } \\
& \mathbb{\Delta}>1 \text { year } \\
& \square \text { no answer }
\end{aligned}
$$

FIGURE 3- Frequency of the children's visits to the dentist

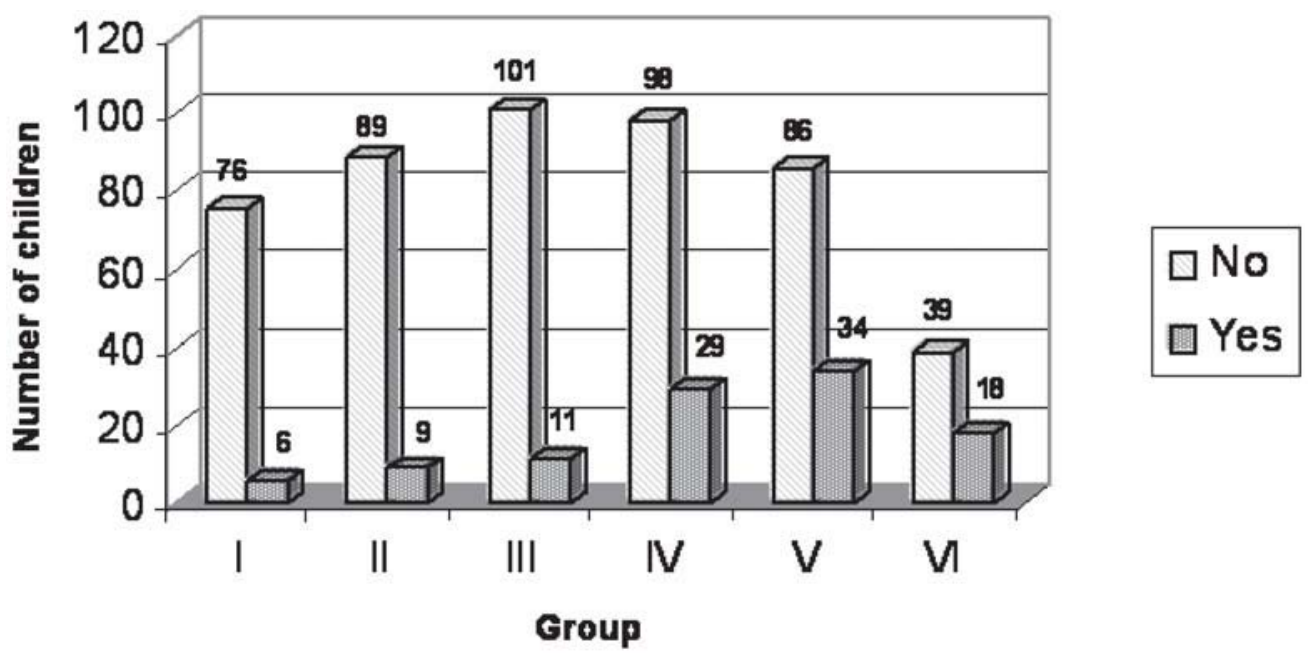

FIGURE 4- Distribution of the children whose parents or caretakers reported the caries experience of their children, according to their age 
TABLE 1- Distribution of the children according to their age

\begin{tabular}{lll} 
Group & Age (months) & Number (\%) \\
\hline I & $0-11$ & $87(13.6)$ \\
II & $12-23$ & $104(16.3)$ \\
III & $24-35$ & $126(19.7)$ \\
N & $36-47$ & $136(21.2)$ \\
V & $48-59$ & $127(19.8)$ \\
V & $60-72$ & $60(9.4)$ \\
\hline
\end{tabular}

shows the distribution of the children whose parents or caretakers reported the caries experience of their children, according to their ages. Moreover, $593(92.7 \%)$ adults reported that they had already had dental caries, $40(6.2 \%)$ had never had dental caries and 7 (1.1\%) did not know.

$327(51.1 \%)$ adults affirmed to believe that the development of an anti-caries vaccine will be possible in a near future, 177 (27.7\%) believed that it will be impossible, and $136(21.2 \%)$ did not know.

\section{DISCUSSION}

The questionnaire used in the present survey was short and contained simple, direct and closed questions. To the best of our knowledge, this was the first study aiming to determine the level of information and usual attitude of parents or caretakers with regards to the transmissibility of caries disease.

The concept of dental caries as an infectious and transmissible disease, convincingly demonstrated by Keyes $^{14}$ (1960), is very well established the scientific field. The transmission of $S$. mutans is a key step towards childhood caries that should be arrested by preventive methods ${ }^{24}$. However, this concept is not known by great part of the population, who answered inadequately the questions regarding this subject in the present study. Furthermore, almost half a century after Keyes' demonstration, clinicians and researchers have only begun to gain insight into the role and relative contribution of bacteria to the caries process ${ }^{7}$.

The mode of transmission of cariogenic bacteria appears to be contact, either direct or indirect. Direct contact is commonly by kissing, so that oral flora is transmitted in the saliva. Indirect contact occurs via objects - a cup, utensil, toothbrush or even a shared toy - that are contaminated with cariogenic bacteria ${ }^{8,21}$. Evidence of MS transmission in humans is based on isolation of common strains within family units, particularly mother-child pairs ${ }^{5,21}$. However, no study has been performed to quantify the effects of mothers and their children sharing food and eating utensils on the subsequent MS colonization in infants ${ }^{8}$.

Transmission is not limited to mother-child relationships. Any caretaker can transmit infection, as can playmates at day care centers if they share toys or utensils that are placed in the mouth ${ }^{21}$. In the present study, both direct and indirect contact was reported by the parents or caretakers as usual attitudes. Although sharing toothbrushes was not reported by them, other bad habits, such as blowing and tasting food, sharing utensils and kissing the children on their mouth, had a high percentage of positive answers. Informing our patients about what should be done for good oral health care and which bad habits should be avoided is a key part of dental caries prevention. Therefore, a current recommendation for dental care providers addressing the issue of interfering with early acquisition of MS is to alter saliva-sharing activities ${ }^{4}$.

In the present study, data regarding the presence of tooth decay were just informed by the adults. Neither the children nor their parents/caretakers underwent intraoral clinical examination during data collection. Thus, it is most likely that the gathered information is not much accurate and that data referring to the presence of dental caries in the surveyed pediatric population were actually underestimated, as many adults are not able to recognize the sings and symptoms of this disease. Mattos-Graner, et al. ${ }^{19}$ (1996) reported that at least $25 \%$ of three-year-old children from various areas of Brazil have detectable caries lesions, many developing lesions within the first 18 months of life. Moreover, nearly half of the children of the present investigation had never visited a dentist, despite the current recommendation that oral health evaluation of the infant by a dental professional should occur before the first birthday ${ }^{5}$.

It is worth mentioning that almost $100 \%$ of the adults reported dental caries experience. Taking into account that there is evidence that mothers with high caries levels have infants with more caries ${ }^{2,6}$, the children of the present study should be targeted for preventive intervention.

In addition, only half of the adults affirmed to believe in the development of an anti-caries vaccine. Nevertheless, the answers regarding this subject were likely more on an intuitive basis rather than on previously acquired knowledge. At present, this is a promising therapy in the prevention of MS colonization in early childhood ${ }^{3,23,25,27}$ that may be available as a more consistent method of controlling the disease ${ }^{3}$.

Few studies have been directed at efforts to interfere with the chain of caries transmission in humans ${ }^{21}$. Detailed knowledge regarding the acquisition and transmission of infectious agents aids to predict which children are at risk ${ }^{6,11}$ and facilitates a more comprehensive approach towards prevention $^{5,11}$. Hence, promotion of public health strategies to reduce the likelihood or level of colonization of mothers and other caretakers by MS is of great interest, since these approaches can delay the infection by cariogenic bacteria of children and consequently decrease their risk for dental caries $^{5,26}$. Additionally, understanding the signals for colonization and growth of cariogenic streptococci in dental biofilms may help to devise more refined and informed techniques, such as the anti-caries vaccine, to weaken those bacteria that can cause us harm ${ }^{25}$. 


\section{ACKNOWLEDGEMENTS}

The authors would like to thank Gentília Borges Carvalho Tavares for her excellent secretarial assistance.

\section{REFERENCES}

1- Alaluusua S, Alaluusua JS, Karjalainen J, Saarela M, Holttinen T, Kallio M, et al. The demonstration by ribotyping of the stability of oral Streptococcus mutans infection over 5 to 7 years in children. Arch Oral Biol. 1994;39(6):467-71.

2- Alaluusua S, Nystrom M, Gronroos L, Peck L. Caries-related microbiological findings in a group of teenagers and their parents. Caries Res. 1989;23(1):49-54.

3- Anusavice KJ. Present and future approaches for the control of caries. J Dent Educ. 2005;69(5):538-54

4- Berkowitz RJ. Causes, treatment and prevention of early childhood caries: a microbiologic perspective. J Can Dent Assoc. $2003 ; 69(5): 304-9$

5- Berkowitz RJ. Mutans streptococci: acquisition and transmission. Pediatr Dent. 2006;28(2):106-9.

6- Caufield PW. Dental caries - a transmissible and infectious disease revisited: a position paper. Pediatr Dent. 1997;19(8):491-8.

7- Caufield PW. Dental caries - an infectious and transmissible disease. Where have we been and where are we going? N Y State Dent J. $2005 ; 71(2): 23-7$

8- Chan KM, King M, Kilpatrick NM. Can infants catch caries? A review of the current evidence on the infectious nature of dental caries in infants. N Z Dent J. 2005;101(1):4-11.

9- Emanuelsson IR, Thorqvist E. Genotypes of mutans streptococci tend to persist in their host for several years. Caries Res. 2000;34(2):133-9

10- Ersin NK, Kocabas EH, Alpoz AR, Uzel A. Transmission of Streptococcus mutans in a group of Turkish families. Oral Microbiol Immunol. 2004;19(6):408-10.

11 - Florio FM, Klein MI, Pereira AC, Gonçalves RB. Time of initial acquisition of mutans streptococci by humans infants. J Clin Pediatr Dent. 2004;28(4):303-8.

12- Grindefjord M, Dahllof G, Nilsson B, Modeer T. Stepwise prediction of dental caries in children up to 3.5 years of age. Caries Res. 1996;30(4):256-66

13- Grönroos L, Saarela M, Mättö J, Tanner-Salo U, Vuorela A, Alaluusua S. Mutacin production by Streptococcus mutans may promote transmission of bacteria mother to child. Infect Immun. $1998 ; 66(6): 2595-600$

14-Keyes PH. The infectious and transmissible nature of experimental dental caries. Arch Oral Biol. 1960;1:304-20.

15 - Kohler B, Andreen I, Jonsson B. The earlier the colonization by mutans streptococci, the higher the caries prevalence at 4 years of age. Oral Microbiol Immunol. 1988;3(1):14-7.

16- Kohler B, Lundberg AB, Birkhed D, Papapanou PN. Longitudinal study of intrafamilial mutans streptococci ribotypes. Eur J Oral Sci. 2003;111(5):383-9.
17- Li Y, Caufield PW, Dasanayake AP, Wiener HW, Vermund SH. Mode of delivery and other maternal factors influence the acquisition of Streptococcus mutans in infants. J Dent Res. 2005;84(9):806-11.

18- Mattos-Graner RO, Li Y, Caufield PW, Duncan M, Smith DJ Genotypic diversity of mutans streptococci in Brazilian nursery children suggests horizontal transmission. J Clin Microbiol. 2001;39(6):2313-6.

19- Mattos-Graner RO, Rontani RM, Gaviao MB, Bocatto HA. Caries prevalence in 6-36-month-old Brazilian children. Community Dent Health. 1996;13(2):96-8

20 - Napimoga MH, Hofling JF, Klein MI, Kamiya RU, Gonçalves RB. Transmission, diversity and virulence factors of Streptococcus mutans genotypes. J Oral Sci. 2005;47(2):59-64.

21- Newbrun E. Preventing dental caries: breaking the chain of transmission. J Am Dent Assoc. 1992;123(6):55-9.

22 - Roeters FJ, van der Hoeven JS, Burgersdijk RC, Schaeken MJ. Lactobacilli, mutans streptococci, and dental caries: a longitudinal study in 2-year-old children up to the age of 5 years. Caries Res. $1995 ; 29(4): 272-9$

23 - Russell MW, Childers NK, Michalek SM, Smith DJ, Taubman MA. A caries vaccine? The state of the science of immunization against dental caries. Caries Res. 2004;38(3):230-5.

24- Slavkin HC. Streptococcus mutans, early childhood caries and new opportunities. J Am Dent Assoc. 1999;130(12):1787-92.

25 - Smith DJ. Dental caries vaccines: prospects and concerns. Crit Rev Oral Biol Med. 2002;13(4):335-49.

26- Tanzer JM, Livingston J, Thompson AM. The microbiology of primary dental caries in humans. J Dent Educ. 2001;65(10):102837.

27-Taubman MA, Nash DA. The scientific and public-health imperative for a vaccine against dental caries. Nat Rev Immunol $2006 ; 6(7): 555-63$ 